\title{
SPATIAL TEMPORAL MAPPING OF SPREAD OF WATER HYACINTH IN WINUM GULF, LAKE VICTORIA
}

\author{
*S.O. Nyawacha; V. Meta; A. Osio \\ Affiliations: Space Generation Advisory Council, ISPRS, Geospatial Society of Kenya, Technical University of Kenya, Department \\ of Survey and Spatial Sciences, Jomo Kenyatta University of Agriculture and Technology, Department of Geomatics Engineering,
} Locate IT, Institution of Surveyors of Kenya

KEY WORDS: Eichhornia crassipes, Water Hyacinth, Turbidity, Water Quality, Modeling, Prediction

\begin{abstract}
:
Water hyacinth (Eichhornia crassipes) is an invasive hydro plant that invaded the waters of Lake Victoria and has since been spreading rapidly affecting the socio-economic livelihood of the community around the Lake. The weed's rapid spread is due to various anthropogenic activities in the surrounding environment among them being the eutrophication of the lake waters.

This study aims at using remote sensing applications and presenting the results of the analysis of the water hyacinth Normalized Difference Vegetation Index (NDVI), water extent, and analysis of correlation with the water quality over time from Sentinel 2 satellite imagery in January 2017 to January of 2021. The analysis aims at understanding the vegetation growth coverage in the five years and sets the basis of monthly predictive modelling of the behavior of water hyacinth. Predictive modelling applies historical statistical data while trying to use trend analysis in predicting the future behavior of a phenomenon. This study also seeks to answer the research question of the role of suspended sediments and dissolved minerals in abating the spread of and growth of water hyacinth.
\end{abstract}

\subsection{INTRODUCTION}

Water hyacinth (Eichhornia crassipes) is an invasive hydro plant (weed) that belongs to the Pontederiaceae family (Mayo and Hanai. 2016). The weed is ravaging some of the freshwater lakes around sub-Saharan Africa today. Water hyacinth is native to the Northern tropics of South America (Cook, 1990) and it rapidly spreads when introduced to previously infested areas, coupled with serious environmental and socio-economic effects (Mitchel et al., 1990). The weed's first reports were in 1895 floating on Lake Victoria after originating from an ornamental pond in Rwanda, into the Kagera River, which is a major tributary of Lake (Osienala, 1990).

It is quite evident that Lake Victoria basin has undergone massive changes ranging from population explosion, industrialization, and environmental degradation with time. On the other hand, the lake has been relevant in supplying ecological goods to the community while economically promoting the economic wellbeing of the community with between 3 to 4 billion U.S dollars per year (Horne and Goldman, 1994).

The massive changes around the basin has brought about extreme environmental impacts, with increased lake eutrophication caused by alien chemical compounds that find their way into the lake from agricultural fields and textile industries that discharge chemical compounds (Mailu., 2001). Bugaari et al., (1998) attributes eutrophication to extreme anthropogenic activities at the lake basin, which promotes the growth of water hyacinth.

Not only does the weed affect the socio-economic nature of the people around the lake, but also the aquatic life cycle, as is attributed to high evapotranspiration while hindering oxygen intake by fauna in the water. This adversely affects the breeding of small fish and specific species leading to their dwindling quantity (Mailu. 2001).

The lake has also experienced the reduction of blue-green algae that fishling consumes (Twongo and Balirwa 1995). The weed also contributes to the reduction of seasonal fish species in the lake specifically the Nile perch (Hecky et al., 1994). The Nile Perch fish species suffers a probable extinction together with half of Lake Victoria 500+ species of the endemic cichlid fishes (Hecky et al., 1994).
In the late 1990s until the start of the 21st century, there was a total paradigm shift leading to the weed's steady spread across the lake, coming to its near end. The phenomenon was due to the flooding that of the lake in late 1998 causing the loss to its initially acquired salinity (Albright et al., 2001). This hypothesis proves the theory that water hyacinth has since thrived in nutrient abundant waters filled with silt and chemical compounds flowing downstream into the lake. The high content of dissolved saline chemicals is attributed to the Industrial activities taking place within the Kisumu metropolitan area, with industries such as textile industries draining their insolvent chemical waste into the lake increasing the level of salinity (Monsanto, 1996).

After the floods subsided, there was a return of the normal activities, with chemical compounds back into the Lake Victoria ecosystem (Kiange and Obuoyo et al.,. 2011). Most often, the chemical compounds contribute to the alkalisation of the waters between 6 to 8 potential hydrogen. Which is a condition that the weed thrives (Tellez et al., 2008). E. crassipes is also uploaded for its absorption rate of the chemical elements dissolved in the waters. Besides, the noxious plant is also tolerable to the high temperatures of between 1 degree to 40 degrees (Wilson et al., 2005), a condition that Winum gulf area experiences.

Despite the effect of nutrients in the waters that promote water hyacinth spread, subsequently, evidence-based research points out that Eichhornia crassipes seed contributes to its growth and spread. The seed is characterized by longevity and stays up to 20 years inactive until a favourable environment is achieved, after which the seed germinates and renews the growth pattern (Malik, 2006).

E. crassipes' presence in Lake Victoria has since caused adverse socio-economic effects on the livelihood of the communities around the lake. Lack of modeling to understand its behavior and provide timely advice to the community has contributed to near-fatal accidents with the weed during fishing (Makhanu. 1997). The clogging nature of the plant has also affected the irrigation plants around the lake by clogging their water pumps, crippling their agricultural activities. The weed has also seen a reduction in fish quantity for the anglers, destabilizing the initial stable fish market, by introducing unprecedented supply demands in the fish market.

*S.O. Nyawacha: snyawacha@gmail.com 
Effect on the community often causes a ripple impact to other sectors as well as affecting the education patterns of the children who are dependent on parents who engage in fishing as an economic activity (Monsanto, 1996).

The spatial-temporal modeling will aid in understanding the natural processes of the hydro plant using an assumed system and a constant period to understand its dynamics. The study will aid in assessing and developing standard habitat assessment protocol, and enable reliable predictions to inform on the likely impact on the shores and the waterways; this will aid decision support in terms of initiatives. The use of the generalized additive model is simple and easily applied in an environmental system of monitoring and assessing various ecosystems phenomenon (Ambelu et al., 2014)

The application of remote sensing in assessing the natural resource dynamics over the years has proven effective (Papastergiadou et al., 2007). The remote sensing technique, when applied in natural resource monitoring, is capable of detecting changes in the aerial extent of water hyacinth across the lake with temporal modeling (Papastergiadou et al., 2007).

This study applies the use of remote sensing and GIS analysis in discovering the extent of the weed across the lake in different years. Modeling the month of January, the resultant information will be the preliminary predictive modeling of the water hyacinth coverage in January of subsequent years, with the capability of forming part of advisory to the anglers of expected coverage of water hyacinth in January, if the climatic conditions remain constant.

\subsection{DATA AND METHODS}

\subsection{Data}

Multi spectral images, with a spatial resolution of 10 meters are applied in the study and analysis of the spread of water hyacinth in Lake Victoria. Sentinel 2 is on boarded a multi spectral imaging instrument (MSI) that delivers high-resolution optical images for land monitoring in particular land location. The MSI provides a 13 spectral band that are combined to give various outputs for application analysis and interpretation.

The temporal coverage of the historical imagery data is acquired every January since 2016 to January of 2020. With sentinel 2 having a $6-12$ days revisit time, there are up to 3 images in a month, for this particular study, imagery is acquired fortnightly resulting to 2 imagery every month for analysis and geovisulisation.

\subsection{Study area}

The study area is the Kenyan part of Lake Victoria around Winum Gulf, with latitude and longitude 0.1 degrees South and 34.2 degrees East respectively.

The location is located around the equator with a depth of 10 meters and a width of 25 kilometres with its extension of approximately 64 kilometres to

Rusinga Island (Obuoyo et al., et al., 2011). This area is one of the most polluted areas, with its proximity to the city that discharges effluents in to the lake plus the

discharges from the agricultural runoff water worsening the situation. This area is also high on chlorophyll, total phosphorus and Secchi content (Obuoyo et al., et al., 2011).

The lake is located within the tropical convergence zone (ITCZ) with bimodal rains that contributes to more than 75 percent of its recharge (Kizza et al., 2009).
The area is also located within the South- East trade wind corridor, which contributes to the heavy rainfall, experienced in the Northern and Western shores of the lake (Awange et al., 2008).

Multispectral image was pre-processed in Google Earth Engine platform. The pre-processing steps was applied to eliminate artefacts that are not related to actual reflectance of the Lake Victoria water extent including sensor effects and atmospheric interference (Young et al., 2017).

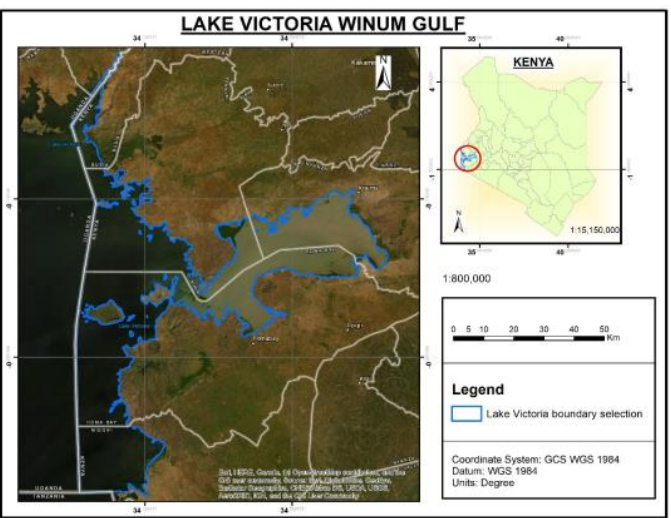

Figure 1: The figure above shows Lake Victoria around Winum Gulf, the Kenyan coast next to Kisumu metropolitan area.

The imagery was later taken through masking of the area of study using the available geometry after the resultant imagery was geo-referenced and co- registered correctly in space. The imagery underwent conversion to radiance applying the level 1 digital number as conversion matrix. Solar correction was paramount in getting rid of top of atmospheric reflectance after which the resultant imagery was in form of surface reflectance and outputted as image composite of the resultant Near Infrared Band, Red and Green bands. The composite resultant clipped image was later cloud masked to less than 10 percent of using mono temporal standard approaches, which leads to 4-5 percent in classification accuracy and 3-10 percentage in commission errors (Mateo-Garcia et al., 2020). The resultant image was then enhanced using histogram equalization to improve the quality of the scene. The available imagery in first half of January was averaged to yield one layer of image.

The resultant image location was validated in existing earth observation resources by overlaying the image in Google earth, after checking the similar version of the world's canvas in Google Earth engine.

\subsection{Imagery processing}

The study area around the Winum Gulf in Lake Victoria, is mapped using Sentinel 2 Multispectral Image, applying quantile classification method, taking the median composite imagery, covering the first half of the month of January (Lillesand and Keifer, 1994). The classes achieved after the model is applied were defined classes of dense and sparse vegetated areas. The classes are categorized based on reflectance values with water hyacinth taking the values from 0.085 to maximum value 1 of NDVI data. This threshold is intended to capture the mixture of water and hyacinth areas. The outputs are binarized to discretely segment the area coverage in hectares as discussed in the next section. 


\subsection{RESULTS AND DISCUSSIONS}

Water hyacinth depicts a near uniform behaviour in coverage when assessed in similar season. 2017 recorded a coverage of approximately 1285.99 hectares of the plant around the shows of Lake Victoria in Kenyan Coast; this is inclusive of the islands that are existence in Lake Victoria that reflect vegetation, as is the water hyacinth. In 2018, the coverage sharply reduced by about $7 \%$ of the area covered to cover approximately 832.58 hectares.

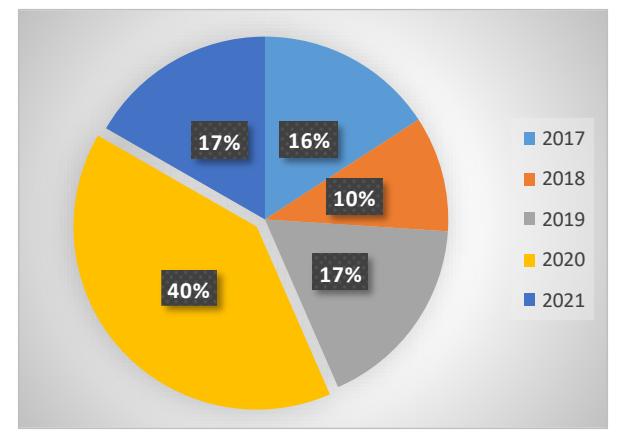

Figure 1: The figure below shows the contribution of each year to the water hyacinth spread in Winum Gulf

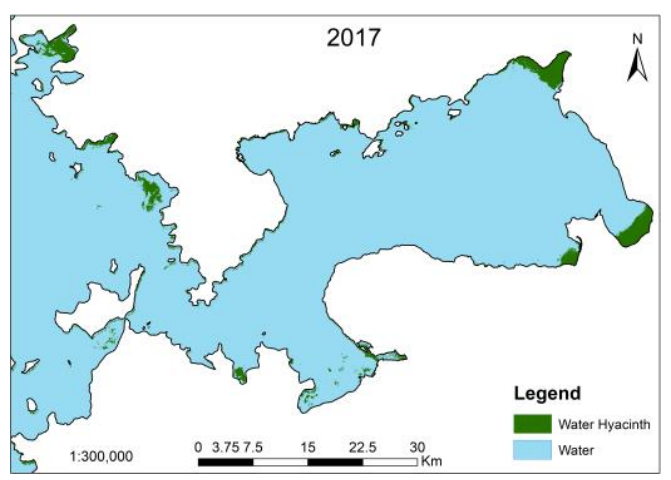

Figure 2: Shows the extent and the location of water hyacinth weed in January of 2017.

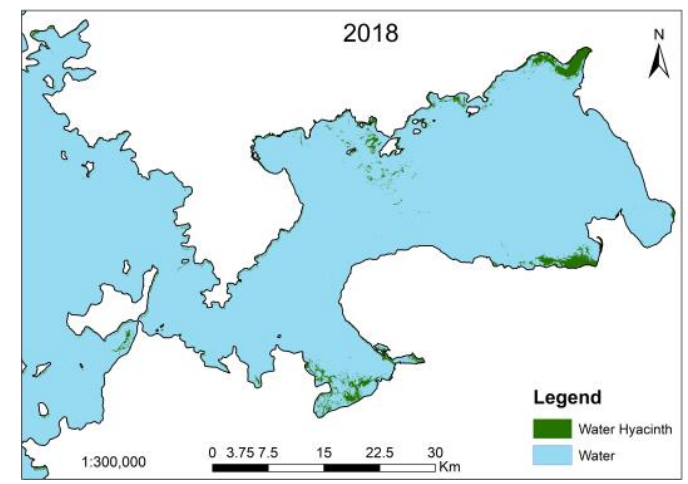

Figure 3: Shows the extent and the coverage location of E. crassipes in Lake Victoria in January of 2017.

Compared to the coverage in 2018, the weed settled around the North Western part of the lake, contrary to the 2017 shoreline coverage.
The amount of Water Hyacinth in 2018 seemed to have drastically reduced, leaving patches of sparsely covered weeds around the lake. Although remote sensing applications of mapping of features on earth, may be subject to interference among other challenges, it is worth noting that the weed has presented the dynamism nature, even after being subjected to similar mapping parameters (Thamaga \& Dube, 2018).

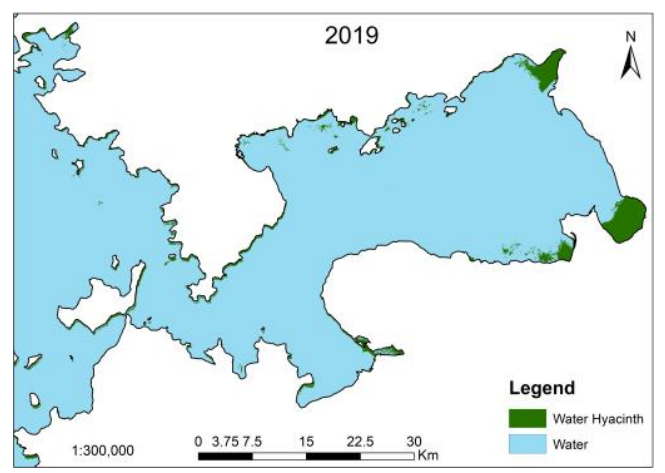

Figure 4: Shows the extent and the coverage location of E. crassipes in Lake Victoria in January of 2019.

This is due to the numerous factors that influence the weed coverage around the lake, including the wind force and direction. There has lacked a clear correlation between the level of eutrophication and the area increase in water hyacinth coverage in the lake. The rate of increase has remained to be approximately constant, covering predictable areas.

However, year 2020 presented the direst state of weed coverage, with media houses reporting waterways and fishing ways blockade. The weed covered the most of the gulf area.

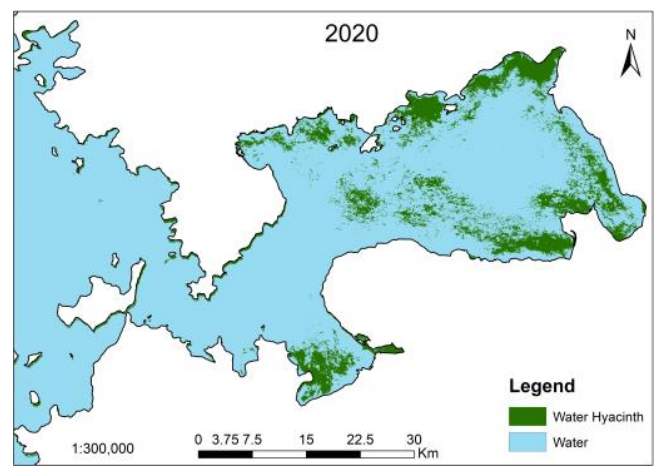

Figure 5: Shows the extent and the coverage location of E. crassipes in Lake Victoria in January of 2020.

The spread in 2021 recorded a drop by approximately $50 \%$ from 2020, with a high agreement from the years 2017, 2018 and 2019 that recorded close area coverage.

However, the increase in water hyacinth coverage in 2020 has no direct evidence to increase of eutrophication in the lakes areas, unless a research is done.

The year 2021, even though Covid 19 had rendered most industrious activities scaled down, with the assumption that there was reduced eutrophication to the lake, the coverage in water hyacinth was reduced similar to coverage in 2019, 2018 and 2017 but again more than 2018, a fully active year. 


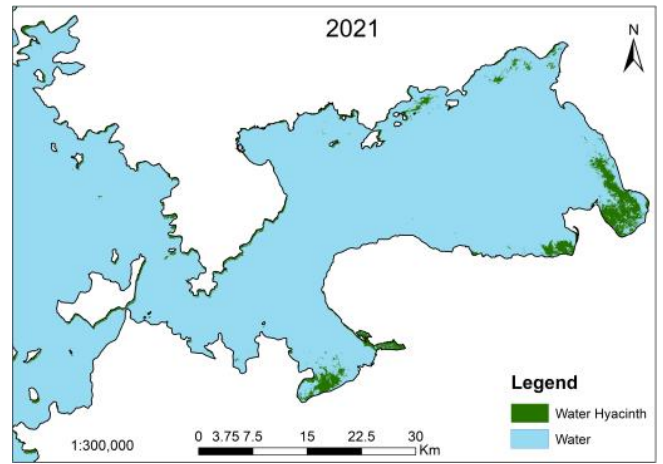

Figure 6: Shows the extent and the coverage location of E. crassipes in Lake Victoria in January of 2020.

The graph below depicts the trend of water hyacinth coverage from 2017 to 2021, with a sharp increase in 2020, and a sharp decrease in 2018 .

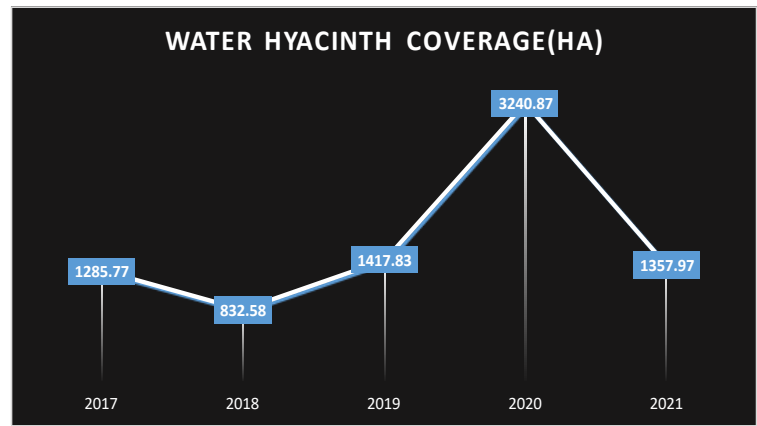

Figure 7: Shows the area change of water hyacinth over the years

When the lakes suspended sediments, turbidity levels and presence of nitrogen content are mapped; there is a close agreement of presence of undissolved pollutants depicting a low water quality of Lake Victoria waters.

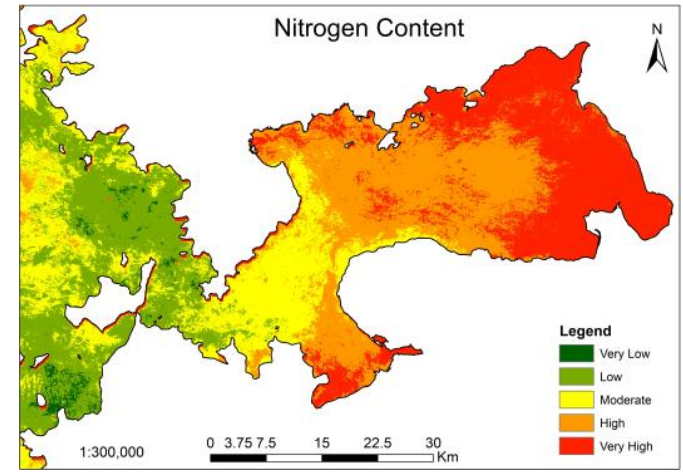

Figure 8: Correlated the presence of nitrogen uptake in water

The above map shows the areas around the shores of Winum gulf, having a high nitrogen content. Green Normalised Difference Vegetation Index (GNDVI) is tidally correlated to the amount of nitrogen content, which is used to map the nitrogen content in Lake Victoria.
The year 2020 turbidity levels are high around the coastal areas of Winum Gulf. This is caused by high concentration of total suspended solid in the lakes water, depicting high level of both eutrophication and siltation in the shallow ends of the Winum Gulf (Elhag et al., 2019) as shown in the Figure 9.

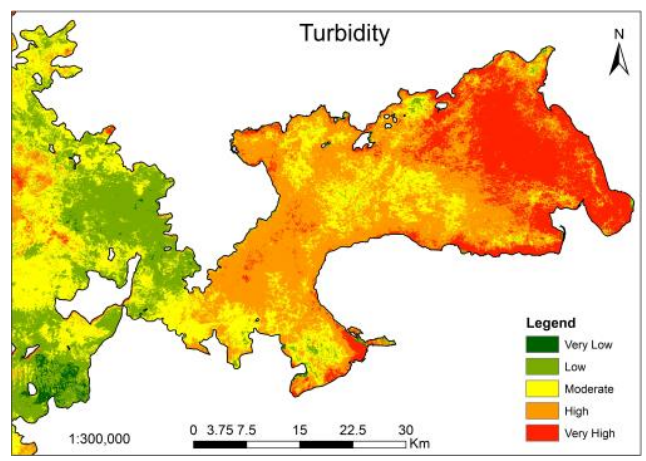

Figure 9: Shows turbidity levels in Lake Victoria

The total suspended sediments show high levels in the deep areas of the lake, where the water is still, however the shallow ends of Winum Gulf, depicts a moderate value of suspended sediment due to the flowing water towards the deep ends. This is evidence of availability of undissolved particles in Lake Victoria's waters.

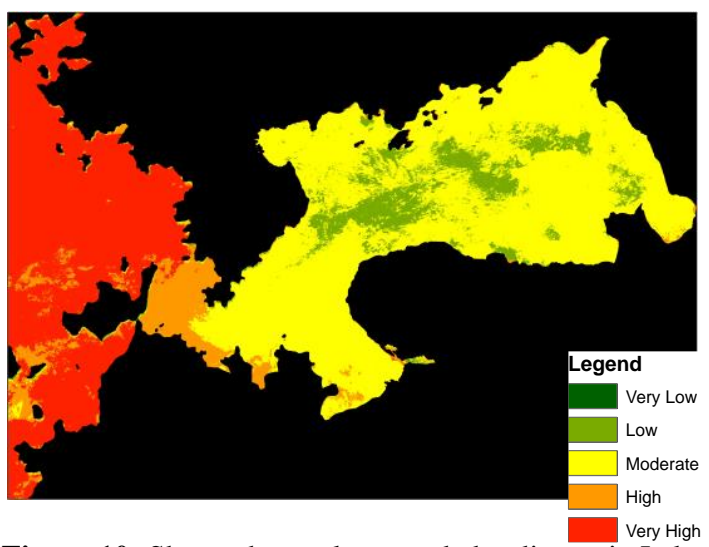

Figure 10: Shows the total suspended sediment in Lake Victoria

The hyacinth spread denotes a small correlation between the values, influenced by outliers as is evidenced in 2020 and 2018 water hyacinth coverage in Figure 11 below.

The gradient depicts a relatively gentle increase in water hyacinth every year as is seen in the following trend. 


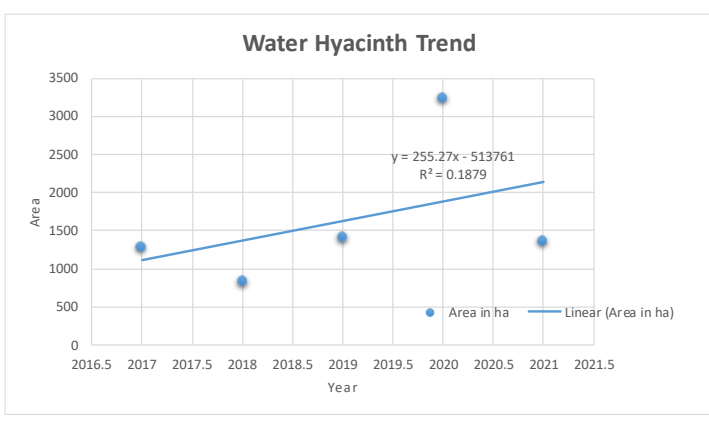

Figure 11: Shows the areas coverage values as well as a trend line

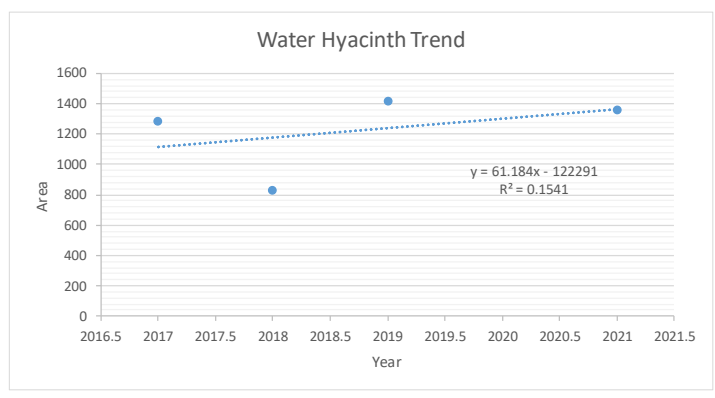

Figure 12: Water Hyacinth trend without 2020 outlier

When the trend is analysed without the outlier, the rate of increase reduces four times thus depicting almost a constant area of coverage of water hyacinth in the Winum Gulf.

However, the coverage of water hyacinth does not depict a direct correlation with the presence of undissolved minerals, nitrogen content and turbidity.

\subsection{CONCLUSION}

Scholars have attributed the presence of water hyacinth to high eutrophication levels in Lake Victoria. In acknowledgement that this is a contributing factor to high nitrogen content, a key nutrient to multiplication of water hyacinth; there is a possibility that water hyacinth is controlled by a more biophysical feature such wind force, wind direction and siltation more than the high eutrophication level. This is an opportunity for future studies to assess the effect of features such as wind direction, wind force as well as siltation on the spread of water hyacinth.

Siltation is a major factor affecting the water overflow around Winum Gulf, and a contributing factor to the already present Hippo grass, which only thrives when the roots get firm grip to the silt. This calls for a more physical based solution such as dredging of the shallow gulf to increase the water retention capacity, as well as depth. This will deprive the Hippo grass the essential anchorage of its roots along the shores. On the other hand, wind plays a major role in blowing the floating weed, most often towards the barriers around the island shores as well as the main land shorelines.

This study as also disclosed a similarity of water hyacinth coverage in Winum Gulf, except for 2020, which appeared to be an outlier. Therefore, there is a high likelihood that the weed is being controlled either by the physical occurrences.

From the aps, the location of water hyacinth in January is predictable, management practice is applicable in these areas, such as physical harvesting, and progressively, the menace that is water hyacinth is resolved only when the rate of harvesting is greater than the rate of increase per year.

\section{REFERENCES}

Albright, T.P., Moorhouse, T.G., and McNabb, T.J. (2004). The Rise and Fall of Water Hyacinth in Lake Victoria and the Kagera River Basin, 1989-2001, J. Aquat. Plant Manage., 42: 73-84.

Bugaari, H., McNabb, T.J., and Moorhouse, T. (1998) The water hyacinth problem in Lake Victoria, East Africa. Kampala, Uganda, Aquatics Unlimited, Report WP-010298, 9p.

Cook, C. D. K, 1990. Origin, autecology, and spread of some of the w orld's most troublesom e aquatic weeds, p. 31-38. In: A. H. Pieterse and K. Murphy (eds.). Aquatic Weeds: The ecology and management of nuisance aquatic vegetation. Oxford University Press, Oxford, England.

Elhag, M., Gitas, I., Othman, A., Bahrawi, J., \& Gikas, P. (2019). Assessment of water quality parameters using temporal remote sensing spectral reflectance in arid environments, Saudi Arabia. Water, 11(3), 556.

González-García, P., Gamboa-González, S., Andrade Martinez, I., \& Hernández-Quiroz, T. (2020). Preparation of activated carbon from water hyacinth stems by chemical activation with $\mathrm{K} 2 \mathrm{CO} 3$ and its performance as adsorbent of sodium naproxen. Environmental Progress \& Sustainable Energy, 39(3), e13366.

Hecky, R.E., Bugenyi, F.W.B., Ochumba, P., Talling, J.F., Mugidde, R., Gophen, M., Kaufman, L., 1994. Deoxygenation of the deep water of Lake Victoria, East Africa. Limnology and Oceanography 39 (6), 1476-1481.

Horne, A. J. and C. R. Goldman. 1994. Limnology, 2nd Edition. McGrawHill, Inc. p. 29.

Kiage, L. M., \& Obuoyo, J. (2011). The potential link between El Nino and water hyacinth blooms in Winam Gulf of Lake Victoria, East Africa: evidence from satellite imagery. Water resources management, 25(14), 3931-3945.

Kizza M, Rodhe A, Chong-Yu, X., Ntale, H. K., \& Halldin, S. (2009). Temporal rainfall variability in the Lake Victoria Basin in East Africa during the twentieth century. Theor Appl Climatol 98(1-2): 119-135

Lillesand, T. M., Kiefer, R. W., \& Chipman, J. W. (2015). Remote sensing and image interpretation. John Wiley \& Sons

Megersa, M., Beyene, A., Ambelu, A., \& Woldeab, B. (2014). The use of indigenous plant species for drinking water treatment in developing countries: a review. J Biodiv Environ Sci, 53, 269-281.

Makhanu, K. S. (1997): Impact of water hyacinth on Lake Victoria. Loughborough University. Conference contribution.

Malik, A. (2007). Environmental challenge vis a vis opportunity: the case of water hyacinth. Environment international, 33(1), 122-138.

Mayo, A. W., \& Hanai, E. E. (2017). Modeling phytoremediation of nitrogen-polluted water using water hyacinth ( Eichhornia crassipes ). Physics and Chemistry of the Earth, Parts $\mathrm{A} / \mathrm{B} / \mathrm{C}$, 100, 170-180. https://doi.org/10.1016/j.pce.2016.10.016. 
Mitchell, D. S., Pieterse, A. H. \&Murphy, K. J. (1990). Aquatic weed problems and management in Africa. In: Aquatic weeds. The ecology and management of nuisance aquatic vegetation (A. H. Pieterse \& A. H. Murphy, eds.). Oxford Science Publ., Oxford, 341-354.

MONSANTO (1996). The Integrated Control and Management of Water Hyacinth

Ochiel, G. S., Njoka, S. W., Mailu, A. M., \& Gitonga, W.

(2001). Establishment, spread and impact of Neochetina spp. on water hyacinth in Lake Victoria, Kenya.

OSIENALA (Friends of Lake Victoria) (1990), Dying Lake Victoria (Ed. by S. O. Aketch), 96p.

Stefanidis, K., \& Papastergiadou, E. S. (2007). Aquatic vegetation and related abiotic environment in a shallow urban lake of Greece. Belgian Journal of Botany, 25-38.

Téllez, T. R., López, E. M. D. R., Granado, G. L., Pérez, E. A., López, R. M., \& Guzmán, J. M. S. (2008). The water hyacinth, Eichhornia crassipes: an invasive plant in the Guadiana River Basin (Spain). Aquatic Invasions, 3(1), 42-53.

Thamaga, K. H., \& Dube, T. (2018). Remote sensing of invasive water hyacinth (Eichhornia crassipes): A review on applications and challenges. Remote Sensing Applications: Society and Environment, 10, 36-46.

Twongo, T. and Balirwa, J.S. (1995) The water hyacinth problem and the biological control option in the highland lake region of the upper Nile basin: Uganda's experience. In: Nile 2002 conference: comprehensive water resources development of the Nile Basin, 13-17 February 1995, Arusha, Tanzania, pp. $1-15$.

Wilson, J. R., Holst, N., \& Rees, M. (2005). Determinants and patterns of population growth in water hyacinth. Aquatic Botany, 81(1), 51-67. 